\title{
A rare case of ascending colon adenocarcinoma incarcerated in an inguinoscrotal hernia: case report and literature review
}

Tien Yew Chern * ${ }^{*}$, Yeng Kwang Tay and Dayashan Shevantha Perera

\begin{abstract}
Background: Inguinal hernias and colorectal cancers are common conditions, but the presentation of a loop of bowel containing cancer within a hernia is rare. Principles of surgery include oncological resection of the involved colonic segment as well as lymphatic drainage. Based on case reports of the last several decades, there have been no reports of a case where the reduction of an inguinoscrotal hernia and oncological colectomy were performed completely laparoscopically. We present the first instance of a completely laparoscopically assisted resection and hernia repair on a patient with $\mathrm{T} 4$ ascending colon cancer. A literature search on recent case reports over the last 30 years has also been presented with a focus on trends in treatment.
\end{abstract}

Case presentation: An 83-year-old man presented for further investigation of his iron deficiency anaemia and was diagnosed with adenocarcinoma of the ascending colon. This was demonstrated radiologically to be found within a large right inguinoscrotal hernia. He underwent a laparoscopically assisted right hemicolectomy and laparoscopic closure of the internal ring and recovered well.

Conclusions: Colorectal cancers within inguinal hernias are rare and can often present with complications such as perforation. As such, treatment has mostly involved an open operation. The last few years have shown feasibility of a laparoscopic approach and can be attempted safely when indicated.

Keywords: Hernia, Inguinoscrotal hernia, Indirect hernia, Ascending colon cancer, Incarcerated cancer, Incarcerated adenocarcinoma, Incarcerated bowel cancer

\section{Background}

The combination of inguinal hernia and colorectal cancer is a very uncommon presentation with less than 40 reports found in the literature. Given its rarity, there has been no standard treatment and therefore often presents to the treating team a therapeutic dilemma. We present a rare case of inguinoscrotal hernia containing an ascending colon adenocarcinoma presenting initially as anaemia for further investigation and eventually treated completely laparoscopically. Given the variability in treatment in the literature and the increasing use of laparoscopic techniques since its introduction in the

\footnotetext{
* Correspondence: tienyew@gmail.com

Department of Colorectal Surgery, St George Hospital, 5/61 Port Hacking Road, Sylvania, NSW 2224, Australia
}

(c) The Author(s). 2018 Open Access This article is distributed under the terms of the Creative Commons Attribution 4.0 International License (http://creativecommons.org/licenses/by/4.0/), which permits unrestricted use, distribution, and reproduction in any medium, provided you give appropriate credit to the original author(s) and the source, provide a link to the Creative Commons license, and indicate if changes were made.

\section{Case presentation}

An 83-year-old man on clopidogrel for coronary artery disease presented to the emergency department of our institution with symptoms of anaemia for the past 3 weeks (Table 1) including increasing fatigue and increasing shortness of breath on exertion. He denied any per rectal bleeding or change in bowel habits and had no significant weight loss. He was noted to have a large partially reducible right inguinoscrotal hernia on examination containing bowel (Fig. 1) which he stated had been present for more than 10 years, which had remained unchanged in size in the last few years.

\section{Springer Open}

1990s, we have also included a literature review with a focus on trends in treatment over the last 30 years. a 
Table 1 Pre-operative blood results

\begin{tabular}{ll}
\hline Blood results & \\
\hline Sodium & $140 \mathrm{mmol} / \mathrm{L}$ \\
Potassium & $5.1 \mathrm{mmol} / \mathrm{L}$ \\
Haemoglobin & $74 \mathrm{~g} / \mathrm{L}$ \\
Haematocrit & $0.244 \mathrm{~L} / \mathrm{L}$ \\
Mean cell volume & $6.6 \mathrm{fL}$ \\
Mean cell haemoglobin & $21.2 \mathrm{pg}$ \\
Mean cell haemoglobin concentration & $303 \mathrm{~g} / \mathrm{L}$ \\
Red cell distribution width & $37.2 \mathrm{fL}$ \\
Iron & $3.2 \mu \mathrm{mol} / \mathrm{L}$ \\
Iron saturation & $3.8 \%$ \\
Transferrin & $3.4 \mathrm{~g} / \mathrm{L}$ \\
Ferritin & $4 \mu \mathrm{g} / \mathrm{L}$ \\
Carcinoembryonic antigen & $2 \mu \mathrm{g} / \mathrm{L}$ \\
\hline
\end{tabular}

His other significant background consisted of hypertension, three previous transient ischaemic attacks, type 2 diabetes mellitus and had a permanent pacemaker for sick sinus syndrome.

Colonoscopy demonstrated a large non-obstructing tumour located at the ascending colon. The tumour was confirmed as adenocarcinoma on histopathology.

Further investigations included a CEA level of $2 \mu \mathrm{g} / \mathrm{L}$ and computed tomography of the chest and abdomen which did not demonstrate metastatic disease but that the ascending colon tumour was located in his right inguinoscrotal hernia (Fig. 2).

He underwent a laparoscopic right hemicolectomy. The caecal pole was adherent to the scrotal sac, and the adhesion was deemed to be inflammatory related rather than direct invasion from the tumour. Laparoscopic

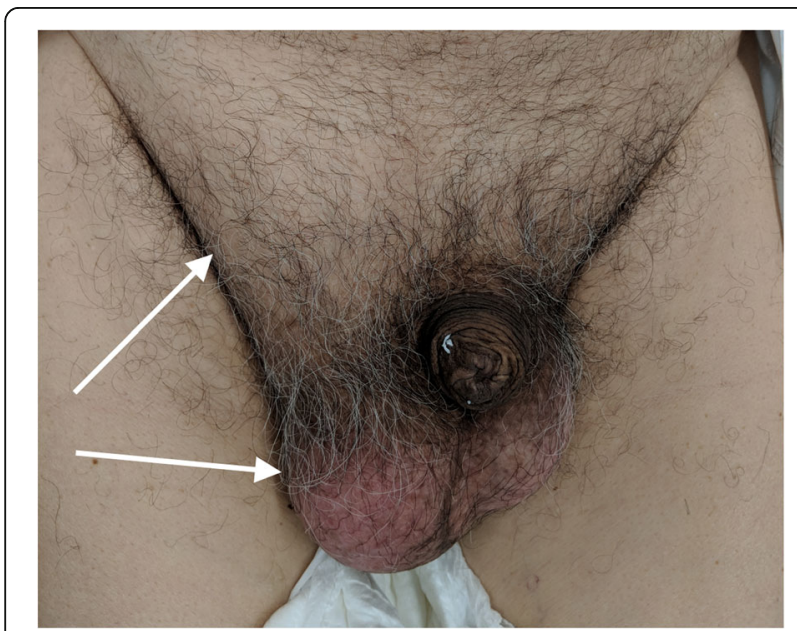

Fig. 1 Pre-operative inguinoscrotal hernia. White arrows point to the right-sided inguinoscrotal hernia adhesiolysis was performed with a moderate degree of difficulty. A $30^{\circ}$ laparoscope was used and inserted into the inguinoscrotal hernia for an angled view (Fig. 3). Bowel manipulation was performed with atraumatic graspers, and adhesiolysis was achieved by an energy device (Olympus Thunderbeat ${ }^{\mathrm{T} \omega}$ ). Further mobilisation followed a standard lateral to medial approach, followed by inferior to superior mobilisation. The omentum was dissected off the transverse colon, lesser sac entered and hepatic flexure to transverse colon was mobilised. The ileocolic pedicle was isolated and stapled, and the diseased colon was delivered through the umbilical port site. A resection and a functional end-to-end anastomosis were performed with the GIA $^{\mathrm{m}} 80 \mathrm{~mm}$ stapler (Medtronic). Pneumoperitoneum was then reestablished, and the deep ring was closed snugly around cord structures with 2-0 V-Loc ${ }^{\mathrm{TM}}$ (Medtronic) non-absorbable sutures laparoscopically.

He had an unremarkable post-op recovery and was discharged home after 7 days. There was no recurrence of the inguinoscrotal hernia at his 4-week post-operative review.

Histopathology confirmed that the ascending colon mucinous adenocarcinoma had invaded partially into serosa with clear resection margins. Four out of 15 lymph nodes were positive. TNM staging was T4aN2aM0 with an R0 resection.

Given the high-risk cancer and poor prognostic features, he is currently being planned for adjuvant capecitabine monotherapy.

\section{Discussion}

The incidence of inguinal hernias in the western population is high with an incidence of $1.7 \%$ with men accounting for $95 \%$ of the presentations [1]. In addition, incidence of colon cancer in the western population is 40 per 100,000 and is currently the fourth leading cause of cancer mortality worldwide [2]. However, together, they form a rare entity with only 38 cases (see Appendix 1) with primary colorectal cancer being reported in the literature worldwide, with all but one cases occurring in males who are mostly elderly (mean age $=71.7$ years) $[3,4]$. Gerhardt in 1938 was the first to report this entity involving the sigmoid colon, and since then most reporters $(71.1 \%)$ have documented sigmoid involvement. Caecal cancers are the second most likely (15.8\%), followed by ascending colon cancers, of which there have been two (5.2\%) including this case report. Due to the rarity of this entity, there has been no clear guideline for treating this.

Therefore, and in the context of advances in surgical treatment especially with the introduction of laparoscopically assisted colectomies since the 1990s, we present a literature review of cases over the last 30 years 


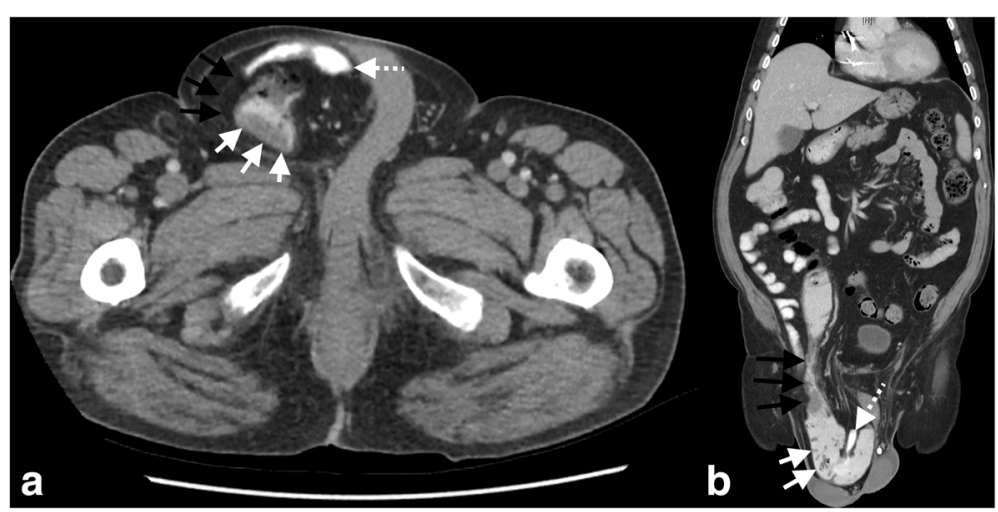

Fig. 2 Computed tomography. a Axial view demonstrating right-sided inguinoscrotal hernia (black arrows) containing large bowel with thickening of the wall representing the ascending colon cancer (white arrows) and herniated terminal ileum (dashed white arrow). b Coronal view demonstrating the rightsided inguinoscrotal hernia (black arrows) with large bowel (white arrows) and terminal ileum (dashed white arrow) herniating through the inguinal canal

(Table 2). While there has been little difference in mean ages (71.3 years in the earlier group and 72.1 years in the later group), we have found that these patients tend to present as complicated hernias with 8 of 17 (47.1\%) being incarcerated, followed by perforation (41.2\%), 1 strangulation (5.9\%) and 1 uncomplicated hernia (5.9\%).

Most patients undergoing the procedure had two incisions, one being the initial incision at the hernia site discovering the pathology followed by a midline incision for the oncological resection. Given the high rates of perforation, eight patients (47.1\%) had an end colostomy (Hartmann's operation). Other than this reported case, there have been two attempts at laparoscopic repair, both in incarcerated but non-perforated hernias, with Pernazza et al. [5] performing a laparoscopic right hemicolectomy and Carr and O'Dair [6] performing a laparoscopic anterior resection.

Most reports document performing the hernia repairs in the same operation although Kouraklis et al. [7] who had formed a loop colostomy delayed that operation for 6 weeks and performed a mesh repair during the colostomy reversal operation. Citing fears of contamination and risk of mesh infection, 11 reporters $(64.7 \%)$ have chosen to perform open nonmesh repairs with 2 of these being intra-abdominal defect closures. Of the three mesh repairs, all have been performed in cases without significant risk of sepsis, although there was perforation without contamination in the case reported by Ruiz-Tovar et al.; nonetheless, there were no reported complications. None of the cases had hernias repaired laparoscopically.

Our case is the second known case of inguinoscrotal hernia containing an ascending colon cancer and to our knowledge the first case in which both the bowel resection and hernia repair were performed completely laparoscopically. The decision to perform the procedure laparoscopically was based on several factors.

1. The benefits of laparoscopic right hemicolectomy are well known, and two recent meta-analyses $[8,9]$ of non-emergent laparoscopic vs open right hemicolectomies have demonstrated advantages intraoperatively with reduced blood loss, postoperatively with reduced time to first flatus, reduced length of stay, reduced post-operative pain, reduced

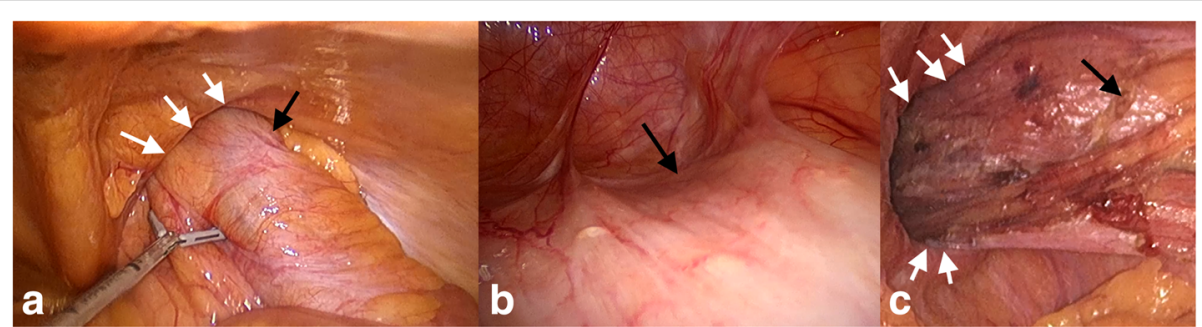

Fig. 3 Intra-operative images. a Laparoscopic view of ascending colon (black arrows) herniating through the deep ring (white arrows). b Angled view within the hernial sac (inguinal canal) using the $30^{\circ}$ laparoscope, black arrows pointing to adherent ascending colon. $\mathbf{c}$ Laparoscopic view of the deep ring (white arrows) with ascending colon (black arrows) and terminal ileum reduced 
Table 2 Cases of bowel cancer presenting within inguinal hernias in the last 30 years

\begin{tabular}{|c|c|c|c|c|c|c|c|c|c|}
\hline Year & First Author & No & Sex & Age & Site & Complications & Treatment & Incision & LOS (days) \\
\hline 1991 [13] & Hale & 22 & M & 85 & Sigmoid & Incarceration & $\begin{array}{l}\text { Hartmann's + intra-abdominal } \\
\text { internal ring closure }\end{array}$ & Midline laparotomy & NA \\
\hline 2003 [12] & Tan & 23 & M & 62 & Sigmoid & Incarceration & $\begin{array}{l}\text { High anterior resection + left } \\
\text { orchidectomy }+ \text { intra-abdominal } \\
\text { closure of hernial defect }\end{array}$ & Left iliac fossa transverse & NA \\
\hline 2003 [7] & Kouraklis & 24 & M & 79 & Sigmoid & Perforation & $\begin{array}{l}\text { Hartmann's + loop colostomy + } \\
\text { interval reversal and open } \\
\text { hernioplasty }\end{array}$ & Left groin & 10 \\
\hline 2003 [16] & Cervinka & 25 & M & 69 & Sigmoid & Incarceration & $\begin{array}{l}\text { Sigmoidectomy + anastomosis } \\
+ \text { defunctioning transverse } \\
\text { colostomy + herniorrhaphy } \\
\text { (Bassini) }\end{array}$ & Left groin & NA \\
\hline 2008 [17] & Slater & 26 & M & 66 & Sigmoid & Incarceration & $\begin{array}{l}\text { Hartmann's + left orchidectomy } \\
+ \text { internal ring closure }\end{array}$ & $\begin{array}{l}\text { Left groin + midline } \\
\text { laparotomy }\end{array}$ & NA \\
\hline 2008 [17] & Slater & 27 & M & 73 & Sigmoid & Perforation & $\begin{array}{l}\text { Hartmann's + left orchidectomy } \\
+ \text { internal ring closure }\end{array}$ & $\begin{array}{l}\text { L groin + Left modified } \\
\text { Rutherford-Morrison }\end{array}$ & NA \\
\hline 2009 [18] & Ruiz-Tovar & 28 & M & 67 & Sigmoid & $\begin{array}{l}\text { Perforation without } \\
\text { contamination }\end{array}$ & $\begin{array}{l}\text { Sigmoidectomy and anastomosis } \\
+ \text { hernioplasty (Lichtenstein) }\end{array}$ & $\begin{array}{l}\text { Left groin }+ \text { midline } \\
\text { laparotomy }\end{array}$ & 7 \\
\hline 2010 [19] & Ko & 29 & M & 84 & Sigmoid & Perforation & Hartmann's + herniorrhaphy & Laparotomy & Deceased \\
\hline 2010 [20] & Mai & 30 & M & 83 & Sigmoid & Strangulation & Hartmann's + herniorrhaphy & $\begin{array}{l}\text { Lower midline + left } \\
\text { groin }\end{array}$ & NA \\
\hline $2011[5]$ & Pernazza & 31 & M & 70 & Caecum & Incarceration & $\begin{array}{l}\text { Laparoscopic right hemicolectomy } \\
+ \text { herniorrhaphy }\end{array}$ & $\begin{array}{l}\text { Laparoscopy + bilateral } \\
\text { groin incisions }\end{array}$ & 5 \\
\hline $2012[6]$ & Carr & 32 & M & 65 & Sigmoid & Incarceration & $\begin{array}{l}\text { Laparoscopic high anterior } \\
\text { resection + open biosynthetic } \\
\text { hernioplasty }\end{array}$ & Laparoscopy + left groin & 4 \\
\hline 2013 [21] & Meniconi & 33 & $\mathrm{~F}$ & 78 & Caecum & Incarceration & $\begin{array}{l}\text { Open right hemicolectomy + } \\
\text { herniorrhaphy }\end{array}$ & $\begin{array}{l}\text { Midline laparotomy + } \\
\text { right groin }\end{array}$ & NA \\
\hline $2013[22]$ & Tan & 34 & M & 63 & Sigmoid & Perforation & Hartmann's + herniorrhaphy & $\begin{array}{l}\text { Midline laparotomy + left } \\
\text { groin }\end{array}$ & 10 \\
\hline 2016 [23] & Kulasegaran & 35 & M & 66 & Sigmoid & $\begin{array}{l}\text { Perforation }+ \\
\text { necrotising infection }\end{array}$ & $\begin{array}{l}\text { Hartmann's + debridement + } \\
\text { staged skin graft }\end{array}$ & $\begin{array}{l}\text { Left groin }+ \text { midline } \\
\text { laparotomy }\end{array}$ & NA \\
\hline $2016[24]$ & Diao & 36 & M & 48 & $\begin{array}{l}\text { Transverse } \\
\text { colon }\end{array}$ & Perforation & $\begin{array}{l}\text { Transverse colectomy + } \\
\text { herniorrhaphy + orchidectomy } \\
+ \text { partial scrotectomy }\end{array}$ & Left groin & NA \\
\hline 2017 [25] & Sharma & 37 & M & 84 & Caecum & None & $\begin{array}{l}\text { Open right hemicolectomy + } \\
\text { herniorrhaphy }\end{array}$ & Right transverse & NA \\
\hline 2018 & $\begin{array}{l}\text { Current } \\
\text { report }\end{array}$ & 38 & M & 83 & $\begin{array}{l}\text { Ascending } \\
\text { colon }\end{array}$ & Incarceration & $\begin{array}{l}\text { Laparoscopic right hemicolectomy } \\
+ \text { laparoscopic defect closure }\end{array}$ & Laparoscopy & 10 \\
\hline
\end{tabular}

LOS length of stay

rate of wound infections with oncologically similar results, with similar number of lymph nodes taken, length of resection and rates of recurrence. The only disadvantage has been increased operative time.

2. While our patient presented to the emergency department, the procedure was carried out electively and was initially investigated endoscopically and thence underwent radiological and biochemical investigations allowing for planning and discussion of the planned elective procedure. Given the benefits of laparoscopic right hemicolectomy, we felt that it was in the patient's best interest to proceed laparoscopically with an option to convert to open if required. This was discussed with the patient who agreed and consented to our approach.

3. Given the unusual presentation of the cancer, laparoscopy allowed definition of the disease with minimal trauma and allowed the flexibility of treatment to change if required without committing to a surgical strategy dictated by an open incision.

4. Although bowel was incarcerated within the hernia, the defect was thought to be large given the fact that the colonoscope was able to reach the terminal ileum and hence passing through the inguinal canal within bowel. As such, muscle relaxation and pneumoperitoneum might have allowed reduction of the herniated bowel which was previously non-reducible [5]. 
Given the risk of herniation through the large defect, it was also important that the hernial defect was repaired. With our centre's long experience with laparoscopic hernioplasties, a trans-abdominal preperitoneal (TAPP) approach was considered. As the operation entailed a bowel resection, the wound created was considered clean contaminated, and despite significant reduction in wound infection rates in laparoscopic right hemicolectomies, they remain at 5.3\% [9]. Therefore, a TAPP approach was thought to be unfeasible given the risk of a surgical site infection and that the only barrier between mesh and bowel was dissected peritoneum, putting the mesh at risk of contamination and infection potentially resulting in a difficult re-operation to remove the mesh.

An open approach and tissue repair was also considered with the advantage of being able to excise the sac for histopathological analysis although the benefits remain unclear in primary intrasaccular tumours [3]. Given the benefits of laparoscopic hernioplasties with chronic pain $[10,11]$, it was decided that the hernial defect could feasibly be closed laparoscopically, noting that previous approaches also included open but intra-abdominal closures of the hernial defect or internal ring [12, 13]. This seemed to be a good compromise, and should the hernia recur, the patient could have a laparoscopic hernioplasty electively.

While it has been established that there is no benefit to screening for abdominal cancers endoscopically or radiologically in inguinal hernias [14], any patient presenting with suspicious features such as symptoms of anaemia, per rectal bleeding, weight loss and change in bowel habits should be further investigated.

It has been traditionally advocated that $\mathrm{T} 4$ tumours are to be resected using an open approach. Recent data have challenged that and have shown that a laparoscopic approach can be safe and is not significantly inferior to an open approach in terms of oncologic outcomes and at the same time maintaining the key advantages of laparoscopy as previously described [15].

\section{Conclusions}

An inguinal hernia containing colorectal cancer is rare but serious and can often present with complications such as perforation. We have presented a case of T4 ascending colon cancer within an inguinoscrotal hernia treated completely laparoscopically. Although the data are limited, laparoscopically assisted bowel resections in this context can be safely performed and could be attempted if feasible.

\section{Appendix 1}

Table 3 All cases of bowel cancer presenting within inguinal hernias (adapted from Matsumoto et al. [3] and Slater et al. [17])

\begin{tabular}{|c|c|c|c|c|c|}
\hline No & Sex & Age & Site & First author & Year \\
\hline 1 & M & 54 & Sigmoid & Gerhardt & 1938 \\
\hline 2 & M & 60 & Sigmoid & Fieber & 1955 \\
\hline 3 & M & 66 & Sigmoid & Bruce & 1958 \\
\hline 4 & M & 67 & Sigmoid & Lookanoff & 1960 \\
\hline 5 & M & 74 & Sigmoid & Griffiths & 1964 \\
\hline 6 & M & 68 & Sigmoid & Lees & 1966 \\
\hline 7 & M & 62 & Caecum & Silberman & 1969 \\
\hline 8 & M & 76 & Caecum & Dross & 1973 \\
\hline 9 & M & 73 & Sigmoid & Dross & 1973 \\
\hline 10 & Unknown & & Colon & Dross & 1973 \\
\hline 11 & Unknown & & Colon & Dross & 1973 \\
\hline 12 & M & 71 & Sigmoid & Horvath & 1974 \\
\hline 13 & M & 86 & Ascending colon & Gross & 1980 \\
\hline 14 & M & 73 & Sigmoid & Gross & 1980 \\
\hline 15 & M & 70 & Sigmoid & Kanzer & 1983 \\
\hline 16 & M & 63 & Sigmoid & Siriam & 1986 \\
\hline 17 & M & 85 & Caecum & Siriam & 1986 \\
\hline 18 & M & 80 & Sigmoid & Papas & 1987 \\
\hline 19 & M & 86 & Sigmoid & Lafferty & 1989 \\
\hline 20 & M & 75 & Sigmoid & Lafferty & 1989 \\
\hline 21 & M & 66 & Sigmoid & Lafferty & 1989 \\
\hline 22 & M & 85 & Sigmoid & Hale & 1991 [13] \\
\hline 23 & M & 62 & Sigmoid & Tan & $2003[12]$ \\
\hline 24 & M & 79 & Sigmoid & Kouraklis & $2003[7]$ \\
\hline 25 & M & 69 & Sigmoid & Cervinka & 2003 [16] \\
\hline 26 & M & 66 & Sigmoid & Slater & $2008[17]$ \\
\hline 27 & M & 73 & Sigmoid & Slater & $2008[17]$ \\
\hline 28 & M & 67 & Sigmoid & Ruiz-Tovar & 2009 [18] \\
\hline 29 & M & 84 & Sigmoid & Ko & 2010 [19] \\
\hline 30 & M & 83 & Sigmoid & Mai & 2010 [20] \\
\hline 31 & M & 70 & Caecum & Pernazza & $2011[5]$ \\
\hline 32 & M & 65 & Sigmoid & Carr & $2012[6]$ \\
\hline 33 & $\mathrm{~F}$ & 78 & Caecum & Meniconi & 2013 [21] \\
\hline 34 & M & 63 & Sigmoid & Tan & 2013 [22] \\
\hline 35 & M & 66 & Sigmoid & Kulasegaran & 2016 [23] \\
\hline 36 & M & 48 & Transverse colon & Diao & 2016 [24] \\
\hline 37 & M & 84 & Caecum & Sharma & 2017 [25] \\
\hline 38 & M & 83 & Ascending colon & Current report & 2018 \\
\hline
\end{tabular}

Abbreviations

LOS: Length of stay; TAPP: Trans-abdominal preperitoneal approach

Availability of data and materials

Data sharing is not applicable to this article as no datasets were generated or analysed during the current study. 


\section{Authors' contributions}

TC, YT and DP were clinicians involved in the inpatient treatment of the patient. TC, YT and DP were all involved in the operation of the patient. TC and $Y T$ were involved in gathering clinical data related to the patient. TC wrote the initial manuscript, which was subsequently edited by $Y T$ and DP. DP approved the final submission of the manuscript. All authors read and approved the final manuscript

\section{Ethics approval and consent to participate}

Not applicable.

\section{Consent for publication}

Consent has been obtained from the patient to publish clinical data, radiologic imaging and pre-operative and intra-operative pictures for the purposes of this case report.

\section{Competing interests}

The authors declare that they have no competing interests.

\section{Publisher's Note}

Springer Nature remains neutral with regard to jurisdictional claims in published maps and institutional affiliations.

Received: 24 April 2018 Accepted: 14 May 2018

Published online: 21 May 2018

\section{References}

1. Jenkins JT, O'Dwyer PJ. Inguinal hernias. Br Med J. 2008;336(7638):269-72.

2. Arnold M, Sierra MS, Laversanne M, Soerjomataram I, Jemal A. Global patterns and trends in colorectal cancer incidence and mortality. Gut. 2017; 66(4):683-91.

3. Matsumoto $G$, Ise $H$, Inoue $H$, Ogawa $H$, Suzuki N, Matsuno S. Metastatic colon carcinoma found within an inguinal hernia sac: report of a case. Surg Today. 2000;30(1):74-7.

4. Boormans JL, Hesp WL, Teune TM, Plaisier PW. Carcinoma of the sigmoid presenting as a right inguinal hernia. Hernia. 2006;10(1):93-6.

5. Pernazza G, Monsellato I, Alfano G, Bascone B, Felicioni F, Ferrari R, et al. Laparoscopic treatment of a carcinoma of the cecum incarcerated in a right groin hernia: report of a case. Surg Today. 2011:41(3):422-5.

6. Carr WR, O'Dair G. A laparoscopic high anterior resection for sigmoid cancer with extraction through incarcerated left inguinal hernia repaired with Permacol mesh. BMJ Case Rep. 2012;2012.

7. Kouraklis G, Kouskos E, Gilnavou A, Raftopoulos J, Karatzas G. Perforated carcinoma of the sigmoid colon in an incarcerated inguinal hernia: report of a case. Surg Today. 2003;33(9):707-8.

8. Ding J, Liao GQ, Xia Y, Zhang ZM, Liu S, Yan ZS. Laparoscopic versus open right hemicolectomy for colon cancer: a meta-analysis. J Laparoendosc Adv Surg Tech. 2013:23(1):8-16.

9. Rondelli F, Trastulli S, Avenia N, Schillaci G, Cirocchi R, Gulla N, et al. Is laparoscopic right colectomy more effective than open resection? A metaanalysis of randomized and nonrandomized studies. Color Dis. 2012;14(8): e447-69.

10. Tschudi JF, Wagner M, Klaiber C, Brugger JJ, Frei E, Krahenbuhl L, et al. Randomized controlled trial of laparoscopic transabdominal preperitoneal hernioplasty vs Shouldice repair. Surg Endosc. 2001;15(11):1263-6.

11. Scheuermann U, Niebisch S, Lyros O, Jansen-Winkeln B, Gockel I. Transabdominal Preperitoneal (TAPP) versus Lichtenstein operation for primary inguinal hernia repair - a systematic review and meta-analysis of randomized controlled trials. BMC Surg. 2017;17(1):55

12. Tan GY, Guy RJ, Eu KW. Obstructing sigmoid cancer with local invasion in an incarcerated inguinal hernia. ANZ J Surg. 2003;73(1-2):80-2.

13. Hale DA, Solla JA. Complete colonic obstruction caused by a sigmoid colon cancer incarcerated in an inguinal hernia sac. South Med J. 1991;84(10): 1280-1.

14. Avidan B, Bardan E, Lang A, Fidder HH, Chowers Y, Bar-Meir S. Colorectal cancer screening in patients presenting with an inguinal hernia: is it necessary? Gastrointest Endosc. 2004;59(3):369-73.

15. Leon P, lovino MG, Giudici F, Sciuto A, De Manzini N, Cuccurullo D, et al. Oncologic outcomes following laparoscopic colon cancer resection for T4 lesions: a case-control analysis of 7-years' experience. Surg Endosc. 2018; 32(3):1133-40.
16. Cervinka A. Surgical images: soft tissue obstructing colon carcinoma in an irreducible scrotal hernia. Can J Surg. 2003;46(5):359-60.

17. Slater R, Amatya U, Shorthouse AJ. Colonic carcinoma presenting as strangulated inguinal hernia: report of two cases and review of the literature. Tech Coloproctol. 2008;12(3):255-8.

18. Ruiz-Tovar J, Ripalda E, Beni R, Nistal J, Monroy C, Carda P. Carcinoma of the sigmoid colon in an incarcerated inguinal hernia. Can J Surg. 2009;52(2):E31-2.

19. Ko KH, Yu CY, Kao CC, Tsai SH, Huang GS, Chang WC. Perforated sigmoid colon cancer within an irreducible inguinal hernia: a case report. Korean J Radiol. 2010:11(2):231-3.

20. Mai CM, Chen CY, Hsu KF, Hsiao CW, Jao SW, Wu CC. Colonic neoplasm in a strangulated inguinal hernia. Rev Esp Enferm Dig. 2008;102(5):339-41.

21. Meniconi RL, Vennarecci G, Lepiane P, Laurenzi A, Santoro R, Colasanti M, et al. Locally advanced carcinoma of the cecum presenting as a right inguinal hernia: a case report and review of the literature. J Med Case Rep. 2013;7(206)

22. Tan A, Taylor G, Ahmed T. Perforated sigmoid colon carcinoma in an irreducible inguinoscrotal hernia. Ann R Coll Surg Engl. 2013;95(7):125-6.

23. Kulasegaran S, Fernando M, Fraser-Jones B, Hammodat H. Perforated sigmoid colon carcinoma within a left inguinal hernia with associated necrotising infection. N Z Med J. 2016:129(1431):93-5.

24. Diao K, Ghosh A. Perforated transverse colon cancer presenting as an incarcerated inguinal hernia. Am Surg. 2016:82(11):320-2.

25. Sharma SK. Inguinoscrotal herniation of a caecal adenocarcinoma. BMJ Case Rep. 2017;

\section{Submit your manuscript to a SpringerOpen ${ }^{\circ}$ journal and benefit from:}

- Convenient online submission

- Rigorous peer review

- Open access: articles freely available online

- High visibility within the field

Retaining the copyright to your article

Submit your next manuscript at $>$ springeropen.com 